\title{
Evaluation of the Mode of Neighboring Group Participation by Divalent Sulfur
}

\author{
Harold Kwart* and Dennis Drayer \\ Department of Chemistry, University of Delaware, Newark, Delaware 19711
}

Received January 24, 1974

\begin{abstract}
Two types of neighboring group participation in intramolecular displacement reactions are distinguished by reference to intermolecular $\mathrm{SN}_{1}$ and $\mathrm{SN}_{2}$ processes. The thiomethyl (in $o$-allylthioanisole) and methoxyl (in 0 allylanisole) groups were compared with the $\mathrm{H}$ in allylbenzene as reference in respect to their participation as neighboring groups in a series of electrophilic and free radical chain addition reactions of the double bond. The addition reagents include $\mathrm{HCOOH}, \mathrm{HBr}, \mathrm{I}_{2}, \mathrm{ArSCl}$, and $\mathrm{BrCCl}_{3}$. Relative rate and product composition data were obtained, where possible, in determining whether the neighboring group had participated and whether such participation had occurred in or subsequent to the rate-determining step. In no case could methoxyl participation $\left(\mathrm{CH}_{3} \mathrm{O}-5\right)$ be identified. The evidence showed, on the other hand, that with the neighboring thiomethyl $\mathrm{CH}_{3} \mathrm{~S}-5$ of the $\mathrm{SN} 1$ type took place to a predominant extent in the HCOOH addition, but without distinctive anchimeric assistance as estimated from the rate effect. The thiomethyl group clearly afforded a large degree of stabilization of the cationic intermediate developing at the neighboring olefin center in both the $\mathrm{I}_{2}$ and $\mathrm{HBr}$ additions. However, no evidence for $\mathrm{CH}_{3} \mathrm{~S}-5$ of the SN1 type could be found in the analogous ArSCl addition reaction. The free radical chain addition of $\mathrm{BrCCl}_{3}$ also displayed no rate or other effects of the neighboring thiomethyl group which could be correlated with stabilization of the intermediate free radical. These and other observations which have been taken into consideration suggest that the most significant factor determining the occurrence of neighboring group participation of the SN1 type is the degree of positive charge developed on carbon in a transition state structured like an ion pair. Neighboring group participation in the transition state of a homolytic process can be distinguished as the SH2 analog of the SN2 type of RS- $n$. Failure to realize the SH1 analog in free-radical chain addition with $\mathrm{BrCCl}_{3}$ can be attributed to insufficient longevity of the radical intermediate.
\end{abstract}

The phenomenon of neighboring group participation ${ }^{1,2}$ has been characterized as the stabilization of a transition state or a reaction intermediate through bonding or partial bonding of a neighboring substituent to the reaction center. ${ }^{1}$ Where the reaction is accelerated by participation of the neighboring group it is said to experience anchimeric assistance. ${ }^{3}$ The increase in rate has also been referred to as intramolecular catalysis, and, just as with intermolecular catalysis, three different types can be identified, namely, nucleophilic, electrophilic, and basic catalysis. ${ }^{4 a}$ Recently the suggestion has been made ${ }^{4 b}$ to call all such cases internal nucleophilic displacements, NDI. This term, however, appears to be too general, particularly as regards characterizing the effects of neighboring groups in the reactions we have studied.

With divalent sulfur, with which we are concerned here (i.e., essentially neighboring group participation by thio ether, or, using the symbolism of Winstein, ${ }^{5} \mathrm{RS}-n$ ), it is theoretically possible to distinguish two subclasses of such intramolecular, nucleophilic catalysis. For convenience these subclasses may be differentiated by reference to the analogous intermolecular displacement processes, $\mathrm{SN}_{\mathrm{N} 1}$ and SN2.

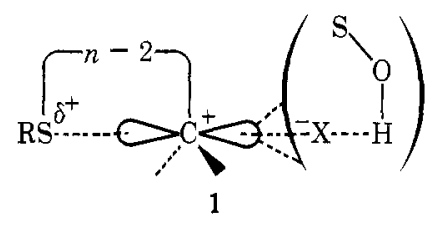

SN1 type of RS- $n$

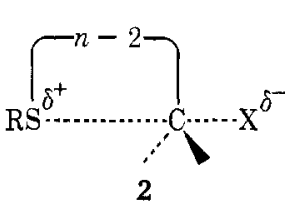

SN2 type of RS- $n$
The view is taken here that an intimate carbonium ion pair such as 1 , which is developing in the $\mathrm{S}_{\mathrm{N}} 1$ transition state, in solution is distinguished from the $\mathrm{SN} 2$ transition state 2 largely by the location of the charge centers and the distribution of charge between them. ${ }^{6,7}$ In either case, however, solvation is required, as has been decisively demonstrated in connection with a clear example of neighboring group participation. ${ }^{8}$ On this basis the essential distinctions between the $\mathrm{SN}_{\mathrm{N}}$ and $\mathrm{SN}_{\mathrm{N}}$ transition states, both of which are leading to ion pair intermedi- ates, can be formulated in the following terms. (a) An SN2 transition state (2) in an uncharged substrate is developing an ion pair in which the positive charge is born largely by the rearward-entering nucleophile, or its associated counterion if the nucleophile is charged; the distance from the carbon seat of the reaction by which the leaving group $\mathrm{X}$ is separated in the transition state is less than twice the sum of the normal ionic radii of carbon and $\mathbf{X}$. (b) An SN1 transition state (1) is developing an ion pair in which the positive charge is born largely by the carbon seat of reaction, and by its substituents involved in diffusion of this charge through resonance and with the aid of electrostatic solvation afforded by solvent and/or neighboring groups. The solvated leaving group $\mathrm{X}$ in 1 is separated from the carbonium ion center by a distance approximating the sum of the normal ionic radii of carbon and the leaving group. Analogous pictures can be described for charged substrates in reactions 1 and 2 .

Thus, in an RS- $n$ reaction of the SN2 type the thio ether group in the transition state is providing synchronous, nucleophilic assistance for the departure of the leaving group at the back side of the reaction center. An RS- $n$ process of the SN1 type, on the other hand, is one in which the development of the carbonium ion at the reaction center is made easier and rate acceleration is experienced through (the equivalent of) rearward solvolytic assistance by the sulfur to the separation by solvent of the departing group at the frontside. That is to say, a solvent-separated ion pair has been formed in the RS-n analog of the SN1 through the ability of the sulfur to provide assistance via nucleophilic stabilization of the rear lobe of the carbonium ion.

It has been contended that rate acceleration might not always be visible ${ }^{9-11}$ in the SN1 type of neighboring group participation. This matter has been the focus of considerable controversy in discussions of the nonclassical carbonium ion. Most recently Schleyer and coworkers ${ }^{12-15}$ have presented evidence to suggest that the normal magnitude of anchimeric assistance by neighboring phenyl in 3-phenyl-2-carbinyl sulfonate ester solvolysis is quite considerable. It is not readily perceptible, however, because of the 
difficulties of sorting out all the rate-influencing effects in solvolysis, including solvent assistance, steric, influences, and inductive effects. Thus, large rate enhancements do not always accompany significant contributions to the solvolytic transition state by participation of neighboring groups.

The most familiar examples of RS- $n$ previously studied, because of the strong nucleophilicity of the neighboring sulfur, can for the most part be readily classified as SN2type transition states leading to ionic or radical intermediates (i.e., either an ionic or radical displacement reaction ${ }^{16,17}$ ). An inventory of such cases ${ }^{18-30}$ can be consulted in assessing the full scope of this type of reactivity. Other examples have been reviewed in the recent literature. ${ }^{2 b, d}$

A significant number of $\operatorname{cases}^{31,32}$ of RS- $n$ cannot be readily interpreted in this way. They involve the participation of sulfide in the electrophilic addition reactions of a neighboring double bond and can be viewed in two equivalent ways. From one viewpoint the neighboring sulfide is increasing the nucleophilicity of the double bond and is thus lowering the activation energy for nucleophilic attack. From another the transition state describes the development of a carbocation facilitated by the influence of a neighboring sulfide. From either viewpoint this reaction may be taken to correspond to the SN1 type of RS- $n$.

The present investigation was undertaken with the objective of establishing the conditions required for sulfide participation of the SN1 type. Sneen and coworkers ${ }^{6 b}$ have urged that carbonium ion pairs intervene in the SN1 solvolysis of secondary substrates. Added nucleophiles such as azide ion in the medium compete with solvent in reaction with the ion pair intermediates. This proposal, which is based on a detailed kinetic analysis, has been sharply challenged by Schleyer ${ }^{7 a}$ and others. ${ }^{33}$ Nonetheless, for purposes of an operational hypothesis in the studies carried out here, experiments were designed on the premise that a simple ion pair of a secondary carbon, analogous to that postulated by Sneen in solvolysis, was capable of forming during electrophilic addition to a terminal double bond. It should, if these circumstances prevail, be greatly (anchimerically) assisted by the participation of a neighboring sulfide in a process resembling the SN1 type of RS- $n$. Another way of expressing this is, if the carbocation intermediate in an electrophilic addition process naturally exists as an ion pair of sufficient longevity, it should experience increased stability manifested as an anchimeric effect resulting from interaction in an SN1 type of RS- $n$ transition state. An analogous statement conceivably might be made for reactions involving free-radical intermediates. The putative ion pairs and radical intermediates in these models chosen for study were generated through additions of common electrophilic and radical reagents to an acyclic double bond.

\section{Results and Discussion}

Probing for RS- $n$ in Electrophilic Addition to a Terminal Double Bond. 1. Addition of Formic Acid. The reactions at $77.5^{\circ}$ of 0 -allylthioanisole (3), 0 -allylanisole (4), and allylbenzene (5) with concentrated formic acid gave in all cases the corresponding $\alpha$-methylphenylethyl formate derivatives, respectively $6 a, 6 b$, and $6 c$. With 4 and 5 this derivative was the exclusive product of reaction. In the case of 3 the derivative $6 \mathrm{a}$ was minor in comparison to the product 7 , which could be isolated as an oil on evaporation of the water and excess formic acid. When the oil was refluxed in fresh formic acid none of the formate derivative was detected. Furthermore, the formate $6 \mathrm{a}$ was unchanged by $>24-\mathrm{hr}$ heating in the formic acid medium. These results indicate that $6 a$ and 7 were formed by entirely different paths.

On prolonged ( 15 days) heating in aqueous formic acid a hydrolytic reaction transformed 7 into a hexane-extractable product 8 , in overall yield (from 3 ) of $\sim 40 \%$ (i.e., $87 \%$ of the product formed). This product was identified by $\mathrm{nmr}$ and mass spectral analysis comparisons with an authentic sample as 2-methyl-1-thiacoumaran (8).

On this evidence and on the basis of its mass spectrum and $\mathrm{nmr}$ the principal product of the reaction of 3 with concentrated formic acid was formulated as 2,3-dihydro-1,2-dimethylbenzo $[b]$ thiophenium formate $(\mathbf{7}$, illustrated in Scheme I). The volatile methyl formate formed

Scheme 1

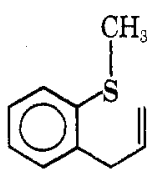

3

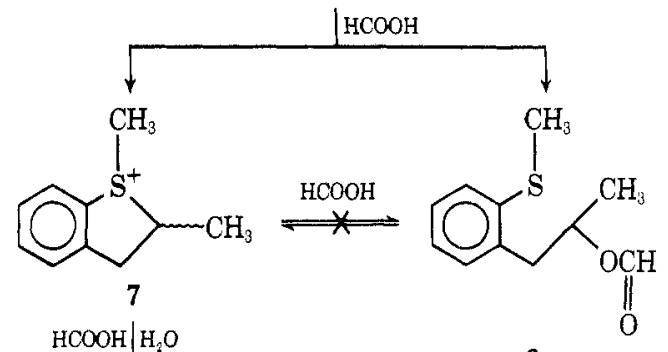

$\mathrm{H}_{2} \mathrm{O}$

$6 \mathrm{a}$

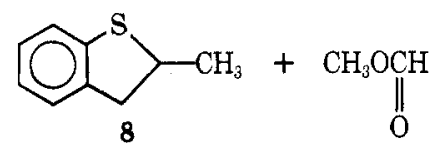

with 8 in a sealed-tube experiment was identified by $\mathrm{nmr}$. These results suggest that sulfide $\left(\mathrm{CH}_{3} \mathrm{~S}-5\right)$ can participate in either the product-forming or rate-determining steps at the neighboring double bond addition centers. The analogous oxy ether $\left(\mathrm{CH}_{3} \mathrm{O}-5\right)$ in 4 apparently did not participate in the product-forming step and, most probably, also not in the rate-determining step leading to $6 \mathrm{~b}$.

The relative rates of $\mathrm{HCOOH}$ addition in the three substrates under comparison are informative in distinguishing between the two competing pathways in Scheme II. If

Scheme II

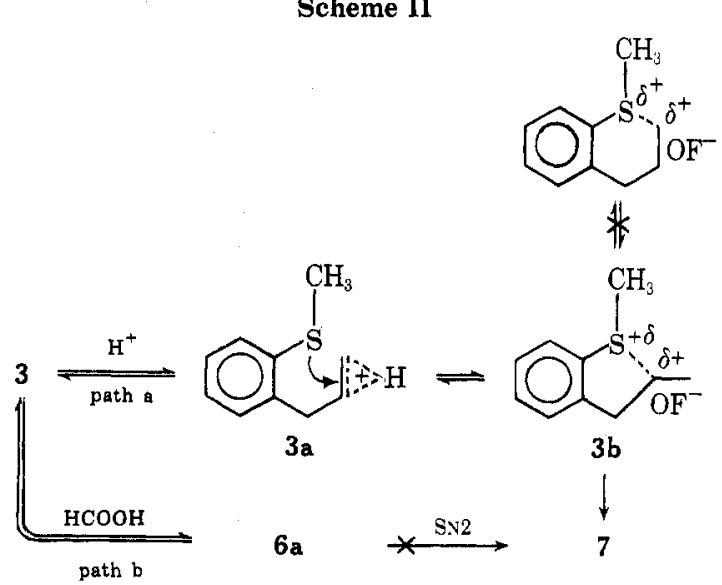

the rate-determining step involved formation of the protonated double bond (or an equivalent $\pi$ complex) without anchimeric assistance, o-allylanisole (4) should undergo reaction less rapidly than 3 and $\mathbf{5}$, since its inductive effect is greatest in destabilizing the positively charged, 
Table I

Part A. Rates of Addition of Formic Acic to Various Allylbenzenes at $77.5^{\circ}$ (Pseudo-unimolecular Kinetics)

\begin{tabular}{lcc}
\hline \multicolumn{1}{c}{ Compd } & $10^{5}, k, \mathrm{sec}^{-1}$ & $\sim k$ relative \\
\hline o-Allylthioanisole $(3)$ & $4.62 \pm 0.18$ & 2.0 \\
o-Allylanisole (4) & $17.5 \pm 0.3$ & 7.5 \\
o-Allylbenzene (5) & $2.32 \pm 0.02$ & 1.0
\end{tabular}

Part B. Solvolysis Rates of

Methoxyphenylalkyl Tosylates ${ }^{34}$ in Formic Acid at $25^{\circ}$

\begin{tabular}{lcc}
\hline \multicolumn{1}{c}{ Compd } & $\begin{array}{c}10^{5} k, \\
\sec ^{-1}\end{array}$ & $\begin{array}{c}\sim k \\
\text { relative }\end{array}$ \\
\hline 2-Methyl-2-phenylpropyl & 1.16 & 1.0 \\
2-(p-Methoxyphenyl)-2-methyl & 83.1 & 72.0 \\
2-(o-Methoxyphenyl)-2-methylpropyl ${ }^{a}$ & 7.7 & 6.5
\end{tabular}

${ }^{a}$ Initial product is the dihydrobenzofuran.

protonated complex. On the other hand, if $\mathrm{CH}_{3} \mathrm{O}-5$ had transpired, a major part of the product to be expected on the basis of results previously observed ${ }^{34}$ in formolysis of 2-(o-methoxyphenyl)-2-methylpropyl tosylate is the dihydrobenzofuran, the oxygen analog of 8 , which was not found. The rate data (see Table I, part A), however, do bear out Ar-3 participation assisted by the o-methoxyl group, and though the rate factor is only 7.5 , this degree of rate enhancement can indeed correspond very considerable anchimeric assistance. ${ }^{15}$ Apparently Ar-3 (assisted by methoxyl substitution) is preferred to $\mathrm{CH}_{3} \mathrm{O}-5$, as found by Winstein, et al. ${ }^{34}$ (Table I, part B), when both are geometrically accommodated by the mechanism of an electrophilic addition to the double bond.

By comparison with $o$-methoxyl the 0 -thiomethyl group shows a smaller rate factor (ca. 2.0). Moreover, this small enhancement of the rate of addition is to be correlated largely with the SN1 type of $\mathrm{CH}_{3} \mathrm{~S}-5$, since $6 \mathbf{a}$ is not the major product, and the formation of 7 from $6 \mathbf{a}$ via a subsequent $\mathrm{SN} 2$ displacement by the neighboring thiomethyl does not take place in the solvolytic medium. It can be inferred, therefore, that the rate-determining step in both cases is the formation of a secondary carbonium ion. In the case of the $\mathrm{CH}_{3} \mathrm{~S}-5$, this carbonium ion is made slightly less than $1 / \mathrm{kcal}$ more stable by neighboring thiomethyl solvation in competition with participation by neighboring aryl and rearward solvation by formic acid. These conclusions can be summarized with reference to the representations 9 and $9 a$.
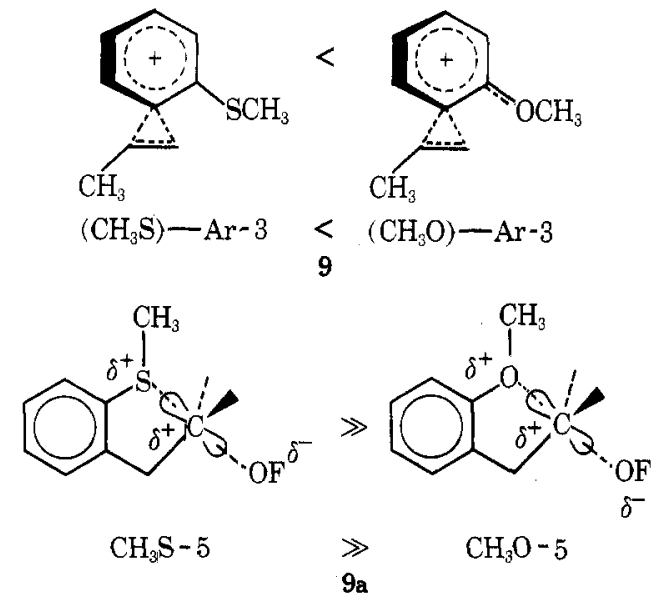

2. Addition of $\mathrm{HBr}$. The addition of $\mathrm{HBr}$ in ether in the presence of antioxidants to 0 -allylanisole (4) has been carried out previously. ${ }^{35 a}$ Only the product of Markovnikov addition, 0 -methoxyphenyl-2-bromopropane (10a), was found. An entirely different result, however, was obtained with 0 -allylthioanisole (3). The thiomethyl analog of 10a, namely $10 \mathrm{~b}$, could not be isolated. After the reaction mixture of 3 with $\mathrm{HBr}$-ether was stirred in the dark at room<smiles>COc1ccccc1CC(C)Br</smiles>

$10 \mathrm{a}$<smiles>Cc1ccccc1CC(C)Br</smiles>

$10 \mathrm{~b}$ temperature for $12 \mathrm{hr}$, a white, hygroscopic solid, 11, precipitated. The mass spectrum showed that $1 \mathrm{~mol}$ of $\mathrm{HBr}$ had been incorporated in 3 in formation of 11 . The $\mathrm{nmr}$ clearly indicated it to be a trans $(11 \mathrm{a}, 89 \%)$ and cis (11b,<smiles>C[C@@H]1Cc2ccccc2[S+]1C</smiles><smiles>C[C@@H]1Cc2ccccc2[S+]1C</smiles>

$11 \%$ ) mixture of the isomeric 2,3-dihydro-1,2-dimethylbenzo[ $b]$ thiophenium bromides. The total isolated yield of 11 was close to $20 \%$. The remainder of the product was readily isolated in $c a .65 \%$ yield and identified as the thiacoumaran 8.

The question to be resolved is whether $10 \mathrm{~b}$ was actually formed, followed by an $\mathrm{SN} 2$ type of $\mathrm{CH}_{3} \mathrm{~S}-5$ participation step, or whether the ion pair intermediate was formed with SN1-type anchimeric assistance by the neighboring thio ether group. The choice between these alternatives can be made by qualitative considerations of the reactivity of a related compound, 0 -(2-bromo-4,4,4-trichlorobutyl)phenylmethyl sulfide (20) (see a subsequent section of this report). The carbon-bromine bond in 20 has the same geometric relationship to the neighboring thiomethyl group as in $10 \mathrm{~b}$. Moreover, it can be assumed that 20 should be somewhat more reactive in an $\mathrm{SN} 2$ displacement because of the strong inductive influence of the electronegative $-\mathrm{CCl}_{3}$ group, which alone distinguishes it from 10b. In an aprotic solvent which fosters the SN2 type of $\mathrm{CH}_{3} \mathrm{~S}-5$ it is found that 20 must be heated at $>105^{\circ}$ for several hours before any extensive conversion to the cyclic displacement reaction product is realized. Since $10 \mathrm{~b}$, on the other hand, cannot be isolated from the $\mathrm{HBr}$ addition to 3 at $0^{\circ}$, in the dark, in an aprotic solvent, it follows that it had never been formed under these reaction conditions. Consequently, it was not a precursor of the formation of the observed thiophenium ions 11a and 11b.

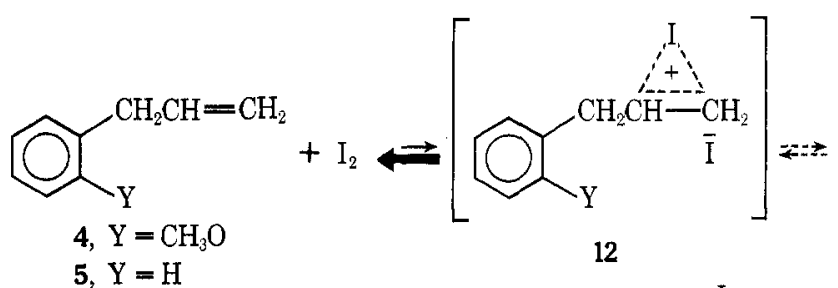<smiles>[Y]c1ccccc1CC(I)CI</smiles>

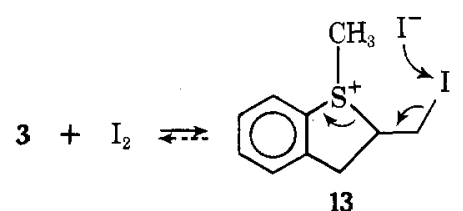

13

3. Reaction with Iodine. Isolated (nonactivated) double bonds do not react with iodine under ordinary conditions. 
This was indeed the case for the double bonds in substrates 4 and 5 , suggesting that the $o$-methoxy substituent provides no activation, i.e., that the equilibrium expressed by eq 1 in these cases lies far to the left.

The behavior of the thiomethyl analog 3 toward iodine was in sharp contrast to that of 4 and $\mathbf{5}$. Within $3 \mathrm{~min}$ after admixture with iodine in glacial acetic acid both reactants were consumed almost quantitatively, as determined by titrimetric analysis with $\mathrm{Na}_{2} \mathrm{~S}_{2} \mathrm{O}_{3}$. However, on standing in air, the formation of some molecular iodine could be noted. These findings, together with the observation that thioanisole does not react with $\mathrm{I}_{2}$, demonstrate that the rapid reaction of 3 and $I_{2}$ involves an equilibrium reaction that lies far to the right with $\mathrm{CH}_{3} \mathrm{~S}-5$ participation at the double bond yielding iodomethyldihydrothiophenium iodide (13, eq 2). Oae and Yano ${ }^{35 b}$ have noted briefly, but without comment, that in aryl and alkyl vinyl sulfides the double bond appeared to be activated toward iodine addition, whereas corresponding oxy ethers did not react with iodine.

The superior ability of sulfur to participate in a $\mathrm{CH}_{3} \mathrm{~S}-5$ transition state of the $\mathrm{SN} 1$ type is manifested in activation of the double bond for an addition process in 3 which completely fails to occur in the absence of such a mechanism. The iodonium ion center in $\mathbf{1 2}$ derives no stabilizing influence from and is therefore completely unreactive toward the neighboring substituent when $\mathrm{Y}=\mathrm{CH}_{3} \mathrm{O}$ (or when the neighboring group is $\mathrm{Ar}$ or $0-\mathrm{CH}_{3} \mathrm{OAr}$ ). Apparently, however, the degree of positive charge on the carbon seat of reaction in 12 , where $\mathrm{Y}=\mathrm{CH}_{3} \mathrm{~S}$, is greater than in the protonated double bond of $3 \mathrm{a}$ with either $\mathrm{Br}^{-}$ or $\mathrm{OF}^{-}$counterions, if one is to judge from the increased reactivity experienced in the iodination reactions.

It will be recognized that the reactivity of $o$-allylthioanisole toward iodine precludes such titrimetric determination of the course of double bond addition reactions, which are normally pursued by means of iodometric methods. The kinetics of 2,4 dinitrobenzenesulfenyl chloride (ArSCl) addition in the case of 3 (for comparison with substrates 4 and 5 ) had to be determined by competition experiments.

4. Addition of Sulfenyl Chlorides. This reaction is well known to occur via an episulfonium ion intermediate in which little charge is developed on carbon; at least one can say that the positive charge on carbon is less than in the protonated double bond in the transition state of protic acid additions. It can be expected that the ability of neighboring groups to participate and provide anchimeric assistance in the double bond addition reactions of 3,4 , and 5 will be determined by the magnitude of the (natural) transition-state charge on carbon. The general mechanism of $\mathrm{ArSCl}$ addition of olefins can be diagrammed and referenced in the following way (Scheme III).

\section{Scheme III}
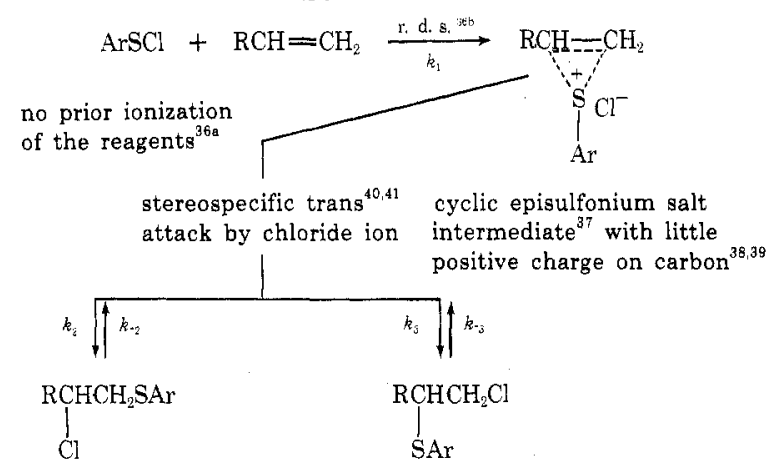

thermodynamically ${ }^{37-42}$ kinetically controlled product ${ }^{37,42}$ controlled product.
Table II

Second-Order Rate Constants for the Addition of ArSCl to Substrate Olefins

\begin{tabular}{cccc}
\hline $\begin{array}{c}10^{3} / T, \\
{ }^{\mathrm{K}}\end{array}$ & $\begin{array}{c}k_{2} \times 10^{4}, \\
\text { l. } \mathrm{mol}^{-1} \mathrm{sec}^{-1}\end{array}$ & $\begin{array}{c}\text { Part B. } \\
10^{3} / T, \\
{ }^{\circ} \mathrm{K}\end{array}$ & $\begin{array}{c}\text { Allylanisole-C- } \\
k_{2} \times 10^{8}, \\
1 . \mathrm{mol}^{-1} \mathrm{sec}^{-1}\end{array}$ \\
\hline 3.050 & $47.1 \pm 0.5$ & 3.089 & $10.1 \pm 0.2$ \\
3.197 & $17.3 \pm 0.2$ & 3.198 & $5.22 \pm 0.15$ \\
3.311 & $7.34 \pm 0.16$ & 3.299 & $2.53 \pm 0.04$ \\
3.372 & $5.17 \pm 0.04$ & 3.378 & $1.70 \pm 0.02$ \\
3.432 & $3.94 \pm 0.08$ & 3.445 & $1.06 \pm 0.01$
\end{tabular}

Table III

Second-Order Rate Constants for Addition of ArSCl to 0 -Allylthioanisole (3) (by Competition with 4)

\begin{tabular}{|c|c|c|c|}
\hline $\begin{array}{c}10^{3} / T, \\
{ }^{\circ} \mathrm{K}\end{array}$ & $\begin{array}{l}\left.k_{4}\right)^{c} \times 10^{8} \\
\text { l. } \mathrm{mol}^{-1} \\
\sec ^{-1}\end{array}$ & $k_{(3) / k_{(4)}}$ & $\begin{array}{c}k_{\{3\}} \times 10^{4} \\
\text { 1. } \mathrm{mol}^{-1} \\
\mathrm{sec}^{-1}\end{array}$ \\
\hline 3.089 & 10.1 & 0.468 & 47.5 \\
\hline 3.198 & 5.23 & 0.440 & 23.0 \\
\hline 3.299 & 2.53 & 0.378 & 9.58 \\
\hline 3.378 & 1.70 & 0.408 & 6.94 \\
\hline 3.445 & 1.06 & 0.362 & 3.84 \\
\hline
\end{tabular}

Cf. cyclohexene ${ }^{43}$

$30.00^{\circ}$
11.6

$(4.5)^{a}$
11.6
${ }^{a}$ Relative rate vs. o-allylanisole. ${ }^{b}$ Relative rate us. $o$-allylthioanisole. ${ }^{\circ}$ Computed from the $k_{2}$ values in Table II.

Table IV

Activation Parameters in the Addition of ArSCl

\begin{tabular}{lrrrr}
\hline \multicolumn{1}{c}{ Substrate } & $E_{\S, \mathrm{kcal} / \mathrm{mol}}$ & $\Delta S^{*},{ }^{a}$ eu & $\begin{array}{c}\Delta G^{*},{ }^{a} \\
\mathrm{kcal} / \mathrm{mol}\end{array}$ \\
\hline Allylbenzene (5) & $13.2 \pm 0.5$ & $-31.0 \pm 1.6$ & 22.1 \\
o-Allylanisole (4) & $12.6 \pm 0.2$ & $-30.9 \pm 0.7$ & 21.4 \\
$\begin{array}{c}\text { o-Allylthioanisole } \\
\text { (3) }\end{array}$ & $13.9 \pm 0.6$ & $-28.3 \pm 0.2$ & 21.9
\end{tabular}

a Computed for the average temperature of all the kinetic runs, $305^{\circ} \mathrm{K}$.

The rates of 4 and 5 in reaction with $\mathrm{ArSCl}$ were readily determined in the usual fashion. ${ }^{43}$ Table II (part A, allyl. benzene, and part $\mathrm{B}, 0$-allylanisole) is a compilation of the rate constants obtained as a function of temperature. Table III displays the corresponding rate constants determined for ArSCl addition to o-allylthioanisole by competition methods. From these values the activation parameters of the respective substrates have been computed and listed in Table IV.

Several conclusions are readily deducible from these data. (1) There is remarkably little difference in the rate of addition of ArSCl to all three substrates; 4 undergoes reaction only slightly faster than $\mathbf{5}$ which, in turn, reacts slightly faster than 3. (2) A comparison with the rate of cyclohexene reaction at the average temperature of measurement $\left(\mathrm{ca} .30^{\circ}\right)$ indicates a total lack of acceleration due to anchimeric assistance; there is clearly no rate effect due to $\mathrm{Ar}-3, \mathrm{CH}_{3} \mathrm{O}-5$, or $\mathrm{CH}_{3} \mathrm{~S}-5$, since cyclohexene reacts faster than all three substrates by factors of 4.5-12. As a consequence of the greatly diminished charge on carbon in the transition state in the rate-determining step, participation that results in stabilization of charge at the seat of reaction is not realized even in the case of the most active neighboring group.

A number of reports ${ }^{31,44}$ have appeared in the literature demonstrating participation by neighboring thio ether largely evidenced by control of the product stereochemistry, However, in the absence of rate data it is difficult to assess the degree of anchimeric: assistance which could possibly be correlated with charge stabilization in the 
rate-determining step. Comparisons of product structure among the three substrates in reaction with $\mathrm{ArSCl}$ were sought for correlation with the relative rate factors.

Thus, the exclusive product of addition of $\mathrm{ArSCl}$ to 4 is the anti-Markovnikov (kinetic) product. Evidently the 0 methoxyphenyl group not only does not participate in the rate-determining step; as a neighboring group with an electron-withdrawing field effect it retards the normal (thermodynamic) product-forming step. This means it acts to divert the chloride counterion attack on the episulfonium intermediate to the least substituted and, normally, the least electron-deficient carbon in the productforming event. The most direct evidence supporting this interpretation arises from the stereochemical results in the addition of $\mathrm{ArSCl}$ to the simplest substrate 5 . Here the product consists of a nearly 50:50 mix of the Markovnikov (thermodynamic) and anti-Markovnikov (kinetic) adducts. Apparently, the removal of the o-methoxy substituent diminishes the electron-withdrawing field effect of the residual phenyl ring to the point where both product-forming modes are competitively active.

The course of addition of 3 , however, is completely altered by the presence of the 0 -thiomethyl group. After 3 days of reaction at $40^{\circ}$ only a single product was obtained and identified as the dihydrothiophene 16 (Scheme IV). In

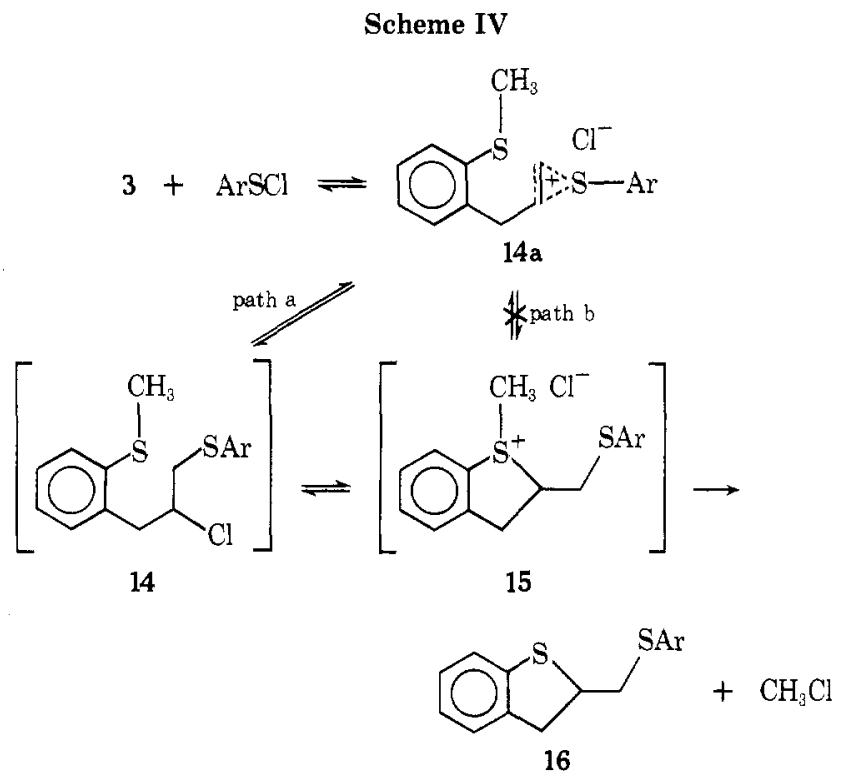

fact, two intermediate products of reaction are possible, both representing the normal Markovnikov direction of the addition process. One of the products, which tends to be insoluble and partially precipitates from the HOAc medium, and which cannot be isolated in sufficiently pure form for a reliable analysis, could be the direct adduct, 14. The second, which also cannot be isolated, is the dihydrothiophenium salt $\mathbf{1 5}$, the necessary precursor of the ultimate product 16 . The formation of 15 represents either SN2 type of displacement of the secondary chloride by neighboring thiomethyl $\left(\mathrm{CH}_{3} \mathrm{~S}-5\right)$ in $\mathbf{1 4}$ via path a, or concomitant attack of thiomethyl via path $\mathrm{b}$ in the rate-determined, episulfonium ion intermediate $14 \mathrm{a}$. The course of reaction, carried out under otherwise normal circumstances in $\mathrm{CD}_{3} \mathrm{COOD}$, has been followed in the $\mathrm{nmr}$. The concentrations of $\mathrm{CH}_{3} \mathrm{Cl}$ and 16 developing in solution were assumed equal; yet the concentration of the common precursor 15 was always below the nmr-detectable limits, since the typical sulfonium methyl resonance near $\sim 3.08$ $\mathrm{ppm}$, plainly evident in all analogous compounds such as, for example, 11, could not be located. Apparently, displacement by chloride on this sulfonium methyl is so
Table V

Product Composition ${ }^{a, c}$ as a Function of Time of Reaction of 3 with $\mathrm{ArSCl}$ in $\mathrm{CD}_{3} \mathrm{COOD}$ at $48.7^{\circ}$

\begin{tabular}{ccc}
\hline & - -Relative concn & \\
\hline Time, hx & $\mathbf{3}]$ & \\
\hline Initial & 23 & Trace \\
2.5 & 10 & 8 \\
8.5 & 7 & 17 \\
20.5 & 6 &
\end{tabular}

a Analyzed by nmr integration (see Experimental Section). ${ }^{b}$ Relative to cyclohexane internal standard expressed as per cent. ' Initial concentration of substrate $3=3.7 \times 10^{-2} \mathrm{M}$. much more rapid than its formation that the steady-state concentration of $\mathbf{1 5}$ is kept to a minimum.

Table $\mathrm{V}$ summarizes the nmr-based observations supporting this conclusion which show that more than half of 3 has been reacted with $\mathrm{ArSCl}$ before even a trace of the ultimate product 16 makes its appearance.

On the basis both of the rate data and product composition as a function of time it may be confidently concluded that path $a$ in Scheme IV is preferred. Thus, in the process of participation by neighboring thio ether, little if any assistance to stabilization of the ion-paired episulfonium intermediate has been gained.

5. Free-Radical Chain Addition. The problem to be addressed here is whether anchimeric effects can be observed in the course of radical chain double bond addition reactions. A comparison of the olefins 3, 4, and 5 in reaction with bromotrichloromethane was chosen for a case study. The reaction of $\mathrm{BrCCl}_{3}$ with 4 initiated by a trace of di-tert-butyl peroxide and heating at ca. $105^{\circ}$ for nearly $20 \mathrm{hr}$ yielded ( $\mathrm{ca} .90 \%$ ) a single product. This was identified as the normal, Markovnikov adduct 17 by a variety of means, including mass spectrum, $\mathrm{nmr}$, and reaction with methanolic $\mathrm{KOH}$ giving rise to $18(60 \%)$, trans-19 (30\%), and cis-19 (10\%). The reaction of 3 with peroxide initia-<smiles>COc1ccccc1CC(Br)CC(Cl)(Cl)Cl</smiles><smiles>COc1ccccc1CC(C=C(Cl)Cl)OC</smiles><smiles>COc1ccccc1C=CC=CCl</smiles>

19

tion under identical conditions afforded a mixture consisting of the Markovnikov adduct $20(60 \%)$ and the cyclic product 21 representing loss of $\mathrm{CH}_{3} \mathrm{Br}$ from 20 .<smiles>Cc1ccccc1CC(Br)C(Cl)(Cl)Cl</smiles>

20<smiles>ClC(Cl)(Cl)Cc1cc2ccccc2s1</smiles>

22<smiles>ClC(Cl)(Cl)CC1Cc2ccccc2S1</smiles>

21

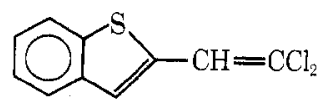

23
Moreover, the total product composition proved to be thermally unstable, for on vacuum distillation the dihydrothiophene component 21 increased greatly at the expense of the adduct 20 . This suggested that 20 was the initially formed product, and had undergone a thermally activated, SN2 type of neighboring group displacement of bromide. In other words, $\mathrm{CH}_{3} \mathrm{~S}-5$ had again taken place in 


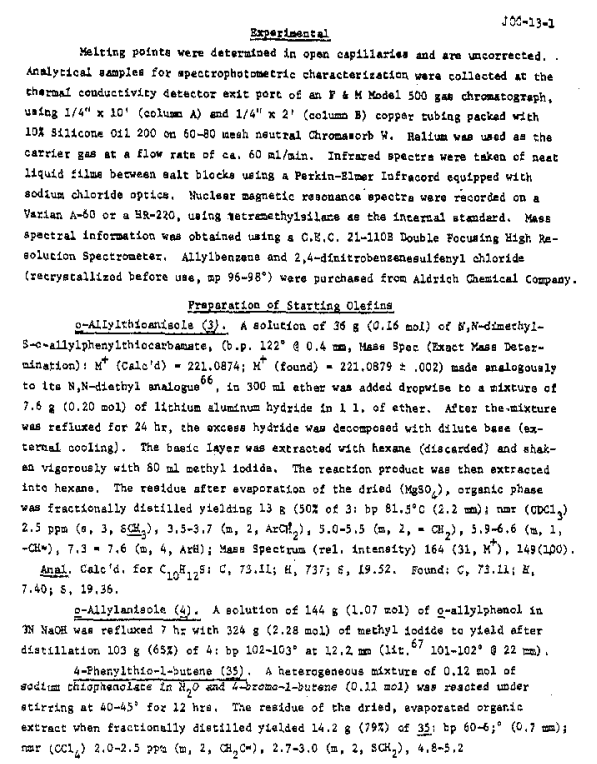

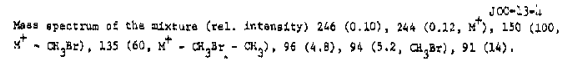

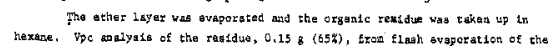

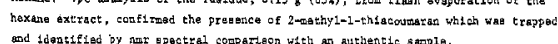

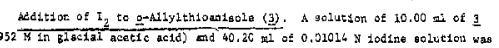

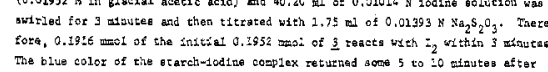

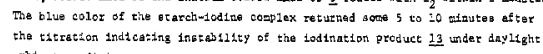

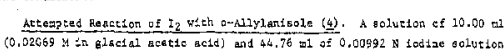

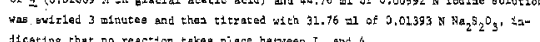

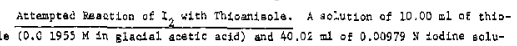

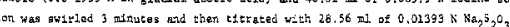

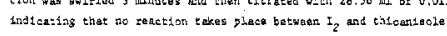

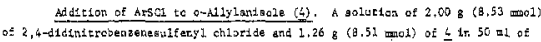

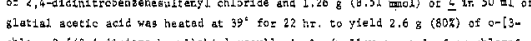

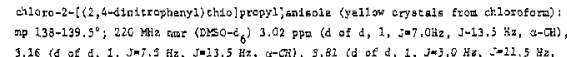

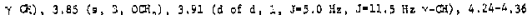

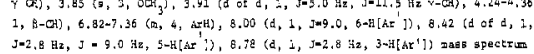

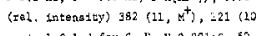

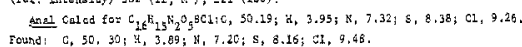

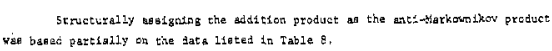

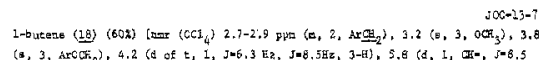

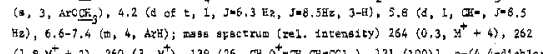

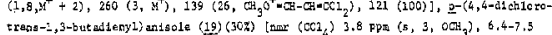

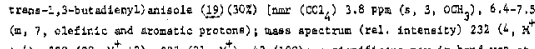

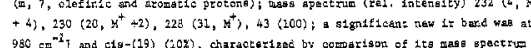

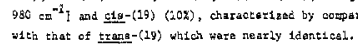

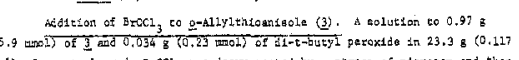

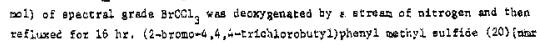

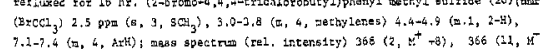

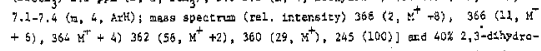

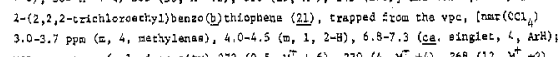

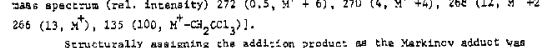

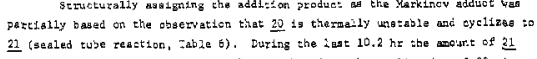

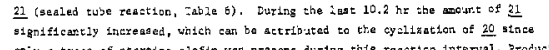

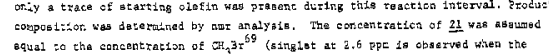

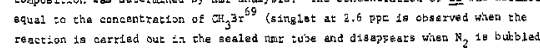
wato the reaction tixture.

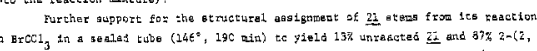

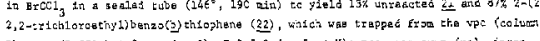

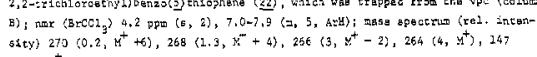
(100, $\mathrm{B}^{+}-\mathrm{CCI}_{\mathrm{j}}$ ).

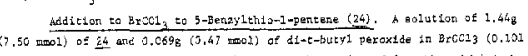

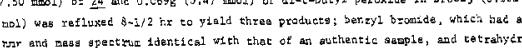

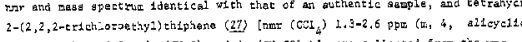

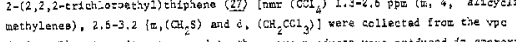

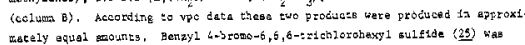

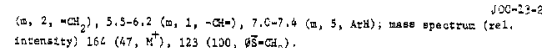

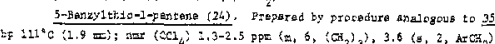

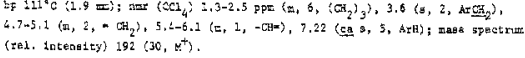

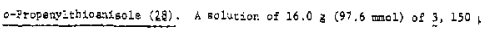

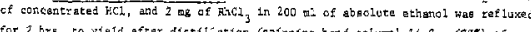

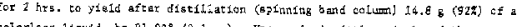

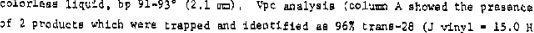

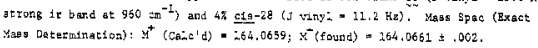

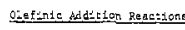

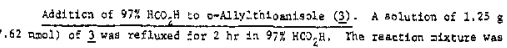

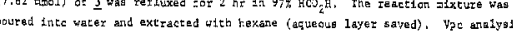

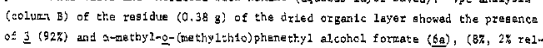

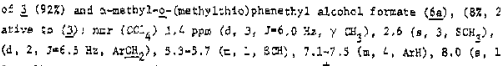

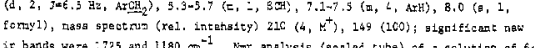

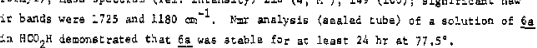

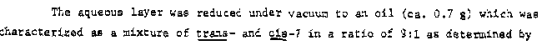

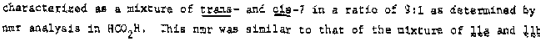

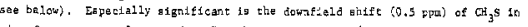

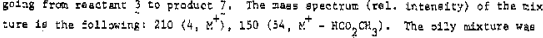

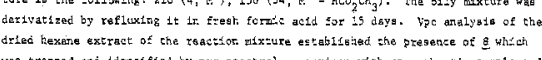

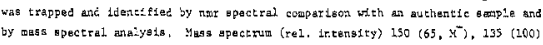

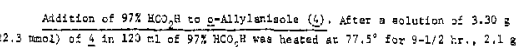

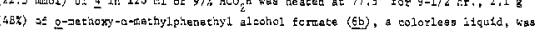

Jis $20-33-5$

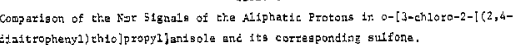

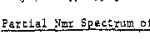

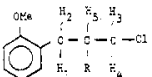

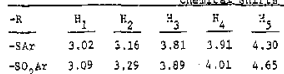

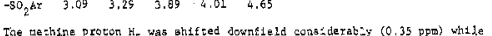

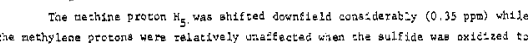

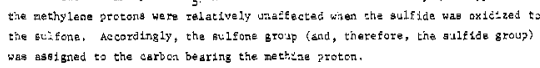

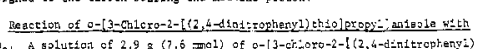

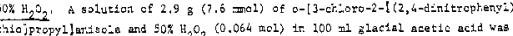

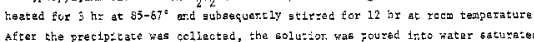

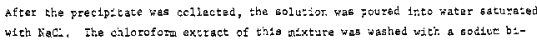

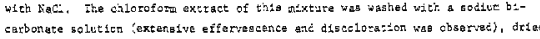

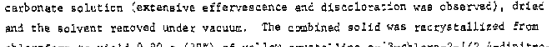

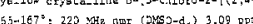

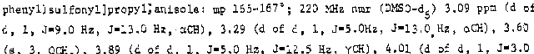

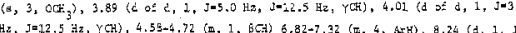

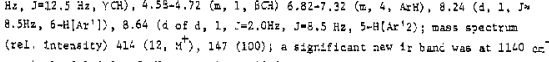

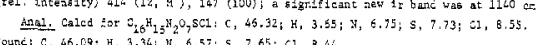
$3.36 ; \mathrm{N}, 6.57 ; 8,7.65 ; \mathrm{Cl}, 3.4$

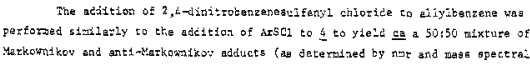
aralys

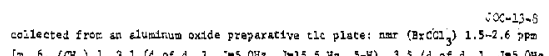

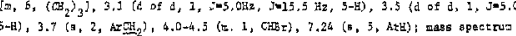

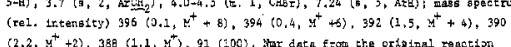

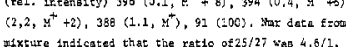

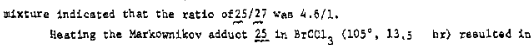

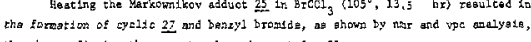

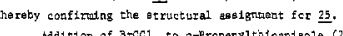

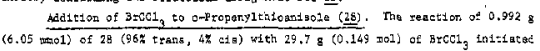

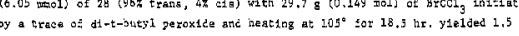

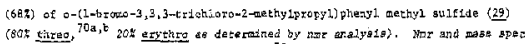

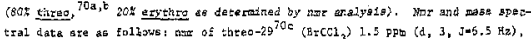

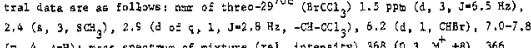

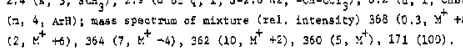

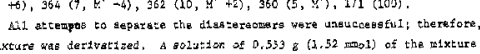

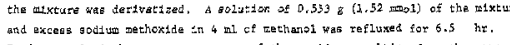

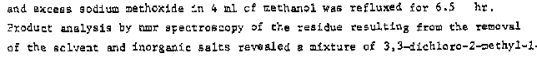

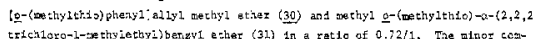

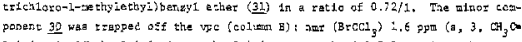

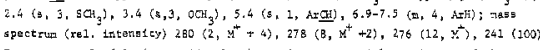

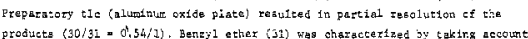

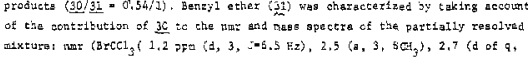

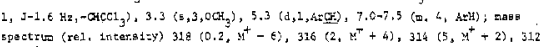

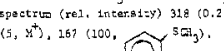

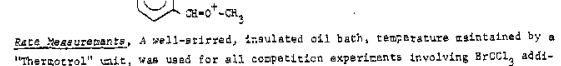

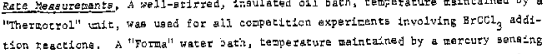

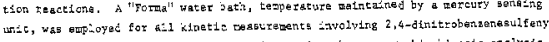

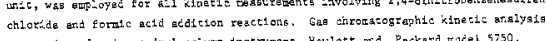

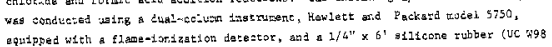

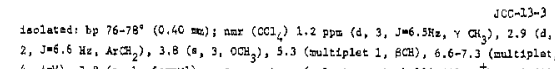

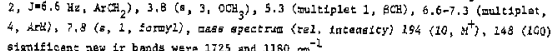

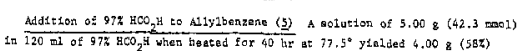

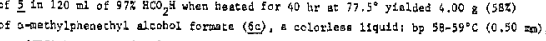

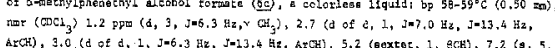

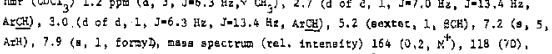

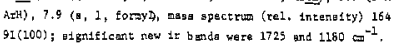

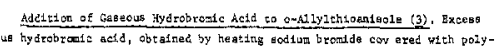

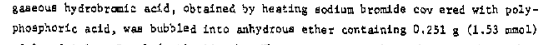

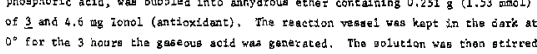

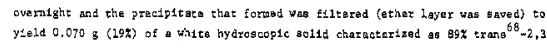

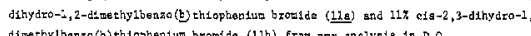

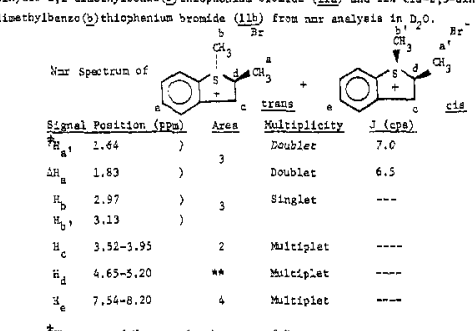

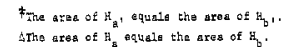

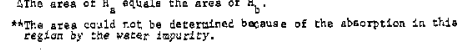

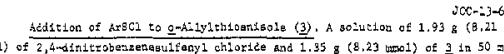

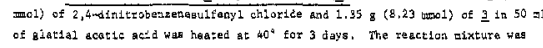

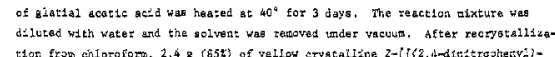

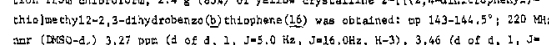

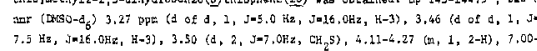

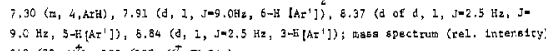

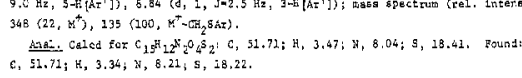

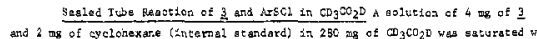

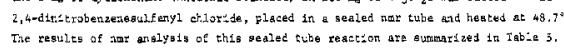

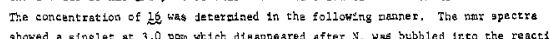

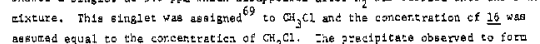

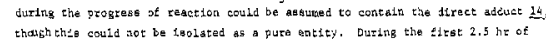
reastion noxe than hes

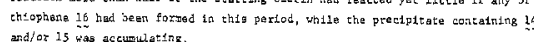

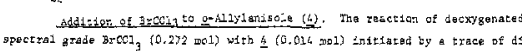

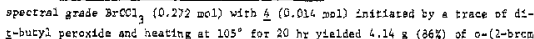

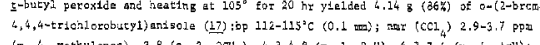

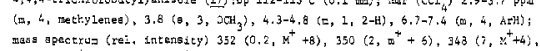

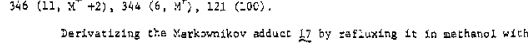

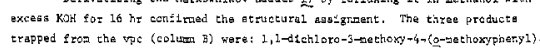

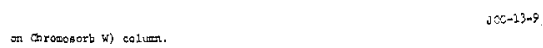

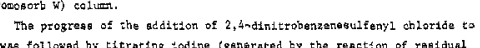

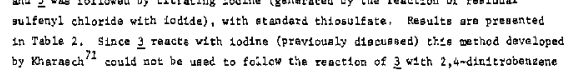

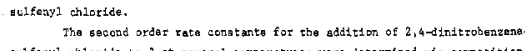

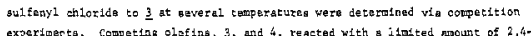

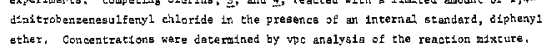

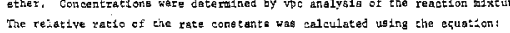

$$
\underline{k_{3}}=\underline{\log _{3}(3)_{1} /(3)^{\prime}}
$$

$x_{4} \log _{0 .}\left(\varphi_{1} /(4)_{\mathrm{f}}\right.$

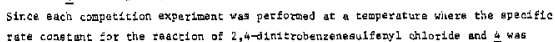

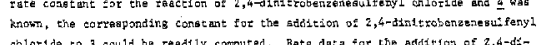

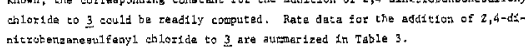

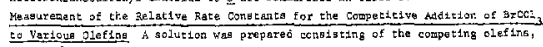

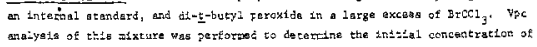

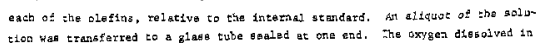

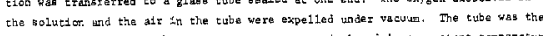

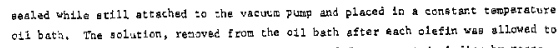

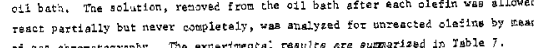

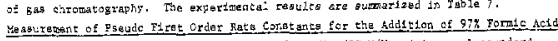

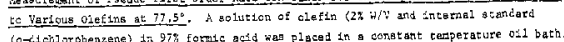

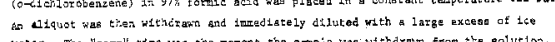

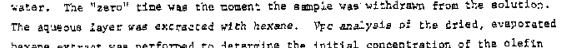

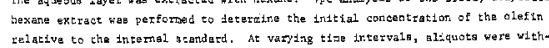

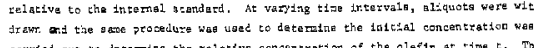

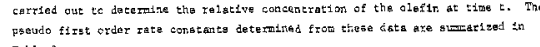


Table VI

Product Composition as a Function of Time of Heating the Reaction of $3+\mathrm{BrCCl}_{3}$ at $100^{\circ}$

\begin{tabular}{ccc} 
& - Product proportions, \%- \\
Time, hr & {$[\mathbf{2 0}]$} & 2 \\
\hline 2.5 & 98 & 2 \\
$9.0^{\alpha}$ & 89 & 11 \\
19.2 & 77 & 23
\end{tabular}

a More than $95 \%$ of 3 had been reacted at this point.

the product-forming step rather than the rate-determining step, followed rapidly by demethylation of the resulting sulfonium ion intermediate through bromide displacement. The progress of this change in product composition occurring at $100^{\circ}$ heating of the reaction mixture in a degassed, sealed tube is given in Table VI. Proof that 20 was indeed the first product formed (which at the elevated reaction temperatures underwent subsequent ring closure) was obtained by carrying out the reaction at low temperatures via photoinitiation. Under these conditions only 20 was formed in $>95 \%$ purity as determined by nmr. The ease with which thermal elimination (including dehydrogenation) occurs in this system is illustrated by the series of compounds evolving from 20 on heating at $146^{\circ}$ in the addition reaction medium in which it was formed; the series includes compounds 21, 22, and 23. The latter (23) was only tentatively identified as a thermal, $\mathrm{HCl}$-elimination product from 22 by the presence of a singlet at 5.9 $\mathrm{ppm}$ in the $\mathrm{nmr}$, but was not isolated in analytically pure form.

The possibility that the aromatic substituent in 3 attenuates the neighboring group capabilities of the thio ether moiety in the radical chain reaction with $\mathrm{BrCCl}_{3}$ was then examined. The addition reaction was carried out with a substrate which did not possess this structural feature, namely, 5-benzylthio-1-pentene (24). This reaction at $c a$. $105^{\circ}$ produced in $8.5 \mathrm{hr}$ a mixture of 25,27 , and benzyl bromide in the ratios indicated in eq 3 . Further heating

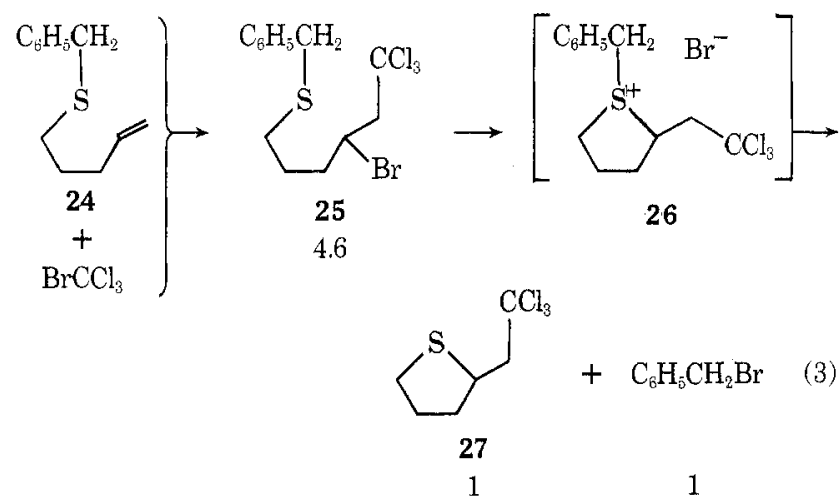

again resulted in the disappearance of the uncyclized component (25), concomitant with increasing 27 and benzyl bromide (in equal amounts). Apparently the missing intermediate 26 , which must be the precursor of 27 , undergoes bromide ion displacement and loss of benzyl bromide too readily to be observed under the thermal conditions of its formation from $\mathbf{2 5}$.

For purposes of a rate comparison (to be discussed subsequently) o-propenylthioanisole (28) which was $96 \%$ trans and $4 \%$ cis was also treated with $\mathrm{BrCCl}_{3}$ and thermal-peroxide initiation. The product collected after an $18.5 \mathrm{hr}$ reaction period in nearly $70 \%$ conversion consisted only of threo (80\%) and erythro (20\%) diastereoisomers of the normal, Markovnikov adduct 29. These structures were identified by mass spectral and nmr criteria, as well as by the course of their reaction with methanolic $\mathrm{NaOCH}_{3}$, shown in Scheme $V$, yielding 30 and 31 in the ratio<smiles></smiles><smiles>CSc1ccccc1C(C(C)Br)C(Cl)(Cl)Cl</smiles>

32<smiles>COC(C(C)=C(C)Cl)c1ccccc1SC</smiles>

33<smiles>COC(c1ccccc1SC)C(C)Cl</smiles>

31
$0.72: 1.0$. This result tends to confirm the interpretation (above) of the course of addition of $\mathrm{BrCCl}_{3}$ to 0 -allylthioanisole (3). There is, evidently, no driving force for $\mathrm{CH}_{3} \mathrm{~S}-5$ participation leading to 32 in the rate-determining step of the free radical chain addition process. If a radical $\mathrm{CH}_{3} \mathrm{~S}-5$ mechanism had been even slightly competitive with the course of addition observed with 28 , previous experience indicates that it should have been possible to find some stable dihydrothiophene such as $\mathbf{3 3}$.

In the interests of evaluating the possibility of any degree of anchimeric assistance in the free radical chain addition process a series of kinetic experiments was conducted by competition methods. The results arrayed in Table VII give no indication of rate differences which can be correlated with any of the structural features of the seven olefins examined.

The largest rate bias, a factor actually less than 2.5, emphasizes that polar substituent influences in most radical chain addition reactions of the double bond are small. ${ }^{45}$ Moreover, polar factors in hydrogen abstraction reactions ${ }^{46}$ do not exceed $\rho=-1.36 .^{47}$ However, while polar substituents exert only minor influence on the homolytic dissociation of the peroxide bond, ${ }^{48}$ exceedingly large accelerations ( $c a .10^{4}$ ), corresponding to $\mathrm{CH}_{3} \mathrm{~S}-5$ participation, have been noted ${ }^{49-51}$ in connection with perbenzoate decomposition. It can be deduced, therefore, that the relative rates of 3 (o-allylthioanisole $=0.95), 4(0$-allylanisole $=1.4$ ), and 5 (allylbenzene $=1.0$ ) signify the total absence of rate effects which could possibly be correlated with anchimeric assistance in the transition state of the $\mathrm{BrCCl}_{3}$ addition reaction.

\section{Conclusions}

Electrophilic Additions. The stereochemistry of the addition of acidic reagents to olefins does not follow a simple pattern and varies from exclusively trans or cis to the formation of nonstereospecific adducts depending on the olefin structure and the nature of the acidic reagent. A few generalizations can be deduced, however. (1) Addition reactions which lead to relatively unstable, shortlived carbocation (or ion-pair) intermediates generally afford trans adducts. Illustrations of this are the addition of $\mathrm{DBr}$ in DOAc to trans-butene, ${ }^{52}$ of $\mathrm{HBr}$ to cyclohexene- 
Table VII

Competitive Rates of Addition of $\mathrm{BrCCl}_{\hat{s}}$ to Various Olefins ${ }^{a}$

\begin{tabular}{|c|c|c|c|c|c|}
\hline Temp, ${ }^{\circ}{ }^{\circ} \mathrm{C}$ & $\begin{array}{l}\text { Time, } \\
\text { min }\end{array}$ & $\begin{array}{c}\text { Olefing }^{c} \\
\text { competing }\end{array}$ & {$[\text { Initial }]^{d}$} & {$[\text { Final }]^{d}$} & $k_{\mathrm{A}} / k_{\mathrm{B}} e^{e}$ \\
\hline 121.00 & 31 & $4 / 3$ & $1.29 / 0.93$ & $0.62 / 0.57$ & $k_{(4)} / k_{\{3)}=1.5$ \\
\hline 121.00 & 57 & $4 / 5$ & $1.57 / 0.94$ & $0.70 / 0.54$ & $k_{(4)} / k_{(5)}=1.4$ \\
\hline 119.70 & 95 & $34 / 28$ & $1.54 / 1.21$ & $0.43 / 0.44$ & $k_{(34)} / k_{(28)}=1.3$ \\
\hline 119.70 & 95 & $34 / 28$ & $1.37 / 1.70$ & $0.39 / 0.58$ & $k_{(34)} / k_{(28)}=1.2$ \\
\hline 119.70 & 92 & $34 / 35$ & $1.52 / 1.56$ & $0.23 / 0.72$ & $k_{(34)} / k_{(35)}=1.5$ \\
\hline 121.00 & 46 & $24 / 5$ & $0.91 / 0.91$ & $0.33 / 0.40$ & $k_{(24)} / k_{(5)}=1.3$ \\
\hline
\end{tabular}

" The gas chromatographic internal standard for the competition at $121^{\circ}$ was diphenyl ether and at $119.7^{\circ} 1,2,4$-trichlorobenzene. ${ }^{b}$ The temperature was held to $\pm 0.1^{\circ} \cdot{ }^{\circ}$ o-Allylanisole (4), 0 -allylthioanisole $(\mathbf{3})$, allylbenzene (5), propenylbenzene (34), o-propenylthioanisole $\left(\mathbf{2 9}, 96 \%\right.$ trans), 4-phenylthio-1-butene $(\mathbf{3 5}), 5$-benzylthio-1-pentene $(\mathbf{2 4}){ }^{d}{ }^{d}$ Initial and final concentrations relative to internal standard. ${ }^{e} k_{\mathrm{A}} / k_{\mathrm{B}}=\log \left(A_{\mathrm{i}} / A_{\mathrm{f}}\right) /\left(B_{\mathrm{i}}\right) /\left(B_{\mathrm{f}}\right)$, where the subscript $\mathrm{i}$ represents the initial and $\mathrm{f}$ the final relative concentrations, that is, at the beginning and end of the reaction period.

$1,3,3-d_{3}$ in $\mathrm{HOAc}^{53}$ and of $\mathrm{HCOOH}$ to 4-tert-butylcyclohexene. ${ }^{54}$ (2) Acid additions which form more stable ion pairs, such as, for example, those having substituted benzylic cations, yield predominantly cis adducts. Illustrations of this route are the cis additions of $\mathrm{DBr}$ to acenaph thalene, indene, and 1-phenylpropene in nonprotic solvents. $^{55}$ (3) Finally, additions that produce highly solvated carbocations yield nearly equimolar amounts of cis and trans adducts, as typified by the acid-catalyzed hydration of 1,2 dimethylcyclohexene. ${ }^{56}$

An attractive conclusion deducible from these generalizations is that the nature of the ion pair intermediate and its lifetime in solution control the stereochemistry of electrophilic addition to the double bond. In a number of cases discussed above $\mathrm{CH}_{3} \mathrm{~S}-5$ participation of the $\mathrm{SN} 2$ type has been observed to occur very readily in the prod. uct-determining step. These facts strongly suggest that there are no steric difficulties associated with thio ether participation in the rate-determining steps of the addition reactions studied. One may speculate how the nature of the ion pairs, i.e., whether or not they involve intimate contact between the counterions, or to what extent solvation energy has been liberated, can influence the stereochemistry of the rate-controlling step. However, the most significant factor appears to be associated with the degree of positive charge developed on carbon in a transition state structured like an ion pair. This factor also is related to the degree of solvation of the ion pair intermediate and its longevity.

A similar conclusion can be drawn from the results above bearing on the occurrence of the SN1 type of $\mathrm{CH}_{3} \mathrm{~S}-5$. This type of neighboring group participation by thio ether has been identified here only in those cases where a significant degree of positive charge would tend to develop on carbon in the activation step of the addition mechanism. In terms of the extent of $\mathrm{CH}_{3} \mathrm{~S}-5$ experienced in the rate-determining step, the results show that iodination $\approx$ hydrobromination in aprotic solvent $\gg \mathrm{HCOOH}$ addition in protic solvent. The $\mathrm{ArSCl}$ addition where almost no charge is developed on carbon ${ }^{38,39}$ gives no evidence of anchimeric assistance via an $\mathrm{SN} 1$ type of $\mathrm{CH}_{3} \mathrm{~S}-5$. This is reminiscent of the report $t^{57}$ that the charge on carbon in the episulfonium salt intermediate ${ }^{37}$ is so scant that nucleophilic attack is often preferred on the sulfur.

The few cases where neighboring sulfur participates in electrophilic addition can be considered to reflect the necessity for a threshold degree of charge on the carbon of the ion pair developing in the activated complex. Thus, the unusually rapid addition of $\mathrm{HCl}$ and $\mathrm{HI}$ to 5-methylthio-1-cyclooctene is explained ${ }^{31}$ as transannular $\pi$-bond activation by the thiomethyl group. The greater stability of the cyclooctyl cation ${ }^{58-60}$ compared to isopropyl may be the controlling influence. An impressive illustration of participation by neighboring sulfur in a stable carbocation intermediate has been furnished by Martin and Basalay, ${ }^{32}$ whereby protonation of 36 gives a cation which may be represented as an equilibrium of $\mathbf{3 7 a}$ and $\mathbf{3 7 b}$ for the reason that it displays only one peak (in the $\mathrm{nmr}$ ) for the two methyls.

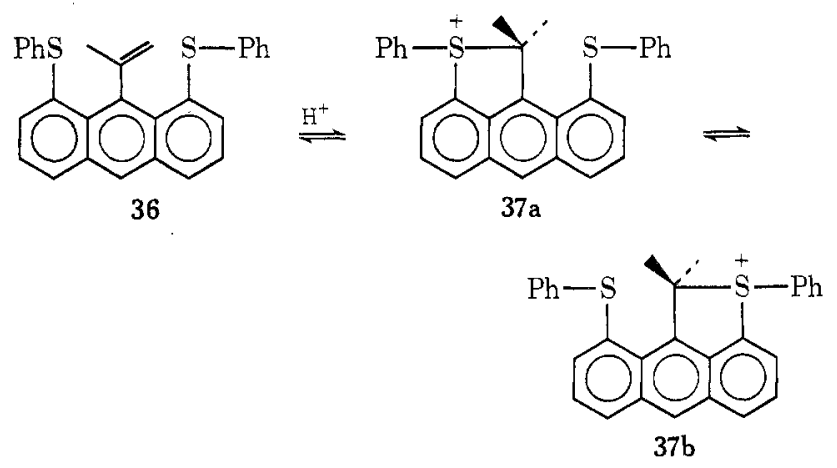

Radical Chain Addition. The reaction of $\mathrm{BrCCl}_{3}$ with olefins is known ${ }^{61}$ to occur in a trans, stepwise manner. The lifetime of the intermediate carbon free radical, however, allows for free rotation. Skell and Woodworth ${ }^{62}$ have reported that the reaction products of both cis- and trans2 -butene are identical in diastereoisomer composition. Thus, free rotation in the radical intermediate about the bond between the ultimate asymmetric centers in the product must be more rapid than its reaction with $\mathrm{BrCCl}_{3}$. This accounts for the 80:20 mixture of diastereoisomers arising from the reaction of $\mathrm{BrCCl}_{3}$ with opropenylthioanisole regardless of the 4:96 cis:trans composition of the starting olefin.

The question to be considered, then, is why, if the intermediate radical had sufficient lifetime to undergo one or more free rotations, did it not experience stabilization through participation by the neighboring, unobstructed, thio ether group. This is a particularly cogent question in view of the results of Martin and coworkers ${ }^{49-51}$ which clearly establish a large degree of anchimeric assistance by thio ether for the homolysis of an $\mathrm{O}-\mathrm{O}$ bond in a $\mathrm{CH}_{3} \mathrm{~S}-5$ process. The answer may lie in the nature of the peroxide cleavage which may be likened to an internal radical displacement process, $\mathrm{SH} 2$. A similar explanation has been proposed by Pryor ${ }^{16}$ for the formation of isobutylene oxide in a hydrogen abstraction from di-tert-butyl peroxide. Apparently, $\mathrm{CH}_{3} \mathrm{~S}-5$ participation of the $\mathrm{SH} 2$ type is just as readily mobilized as the $\mathrm{CH}_{3} \mathrm{~S}$-5-assisted displacements of the SN2 type.

It is possible that failure to observe the analogous $\mathrm{SN}_{1}$ type of $\mathrm{CH}_{3} \mathrm{~S}-5$ process during addition of $\mathrm{BrCCl}_{3}$ to 3 (and other thiomethyl olefins discussed above) may be correlated with inadequate longevity of the radical intermediate in these reactions. Evidently the intermediate must endure for a period longer than is merely necessary 
to account for the diastereomeric product composition. Skell and coworkers ${ }^{63,64}$ have suggested that bridged radi$\mathrm{cal}^{65}$ intermediates can be detected by stereoselective addition results, and claimed evidence for neighboring group assistance in the transition state of radical addition reactions. On the other hand, Kaplan ${ }^{65 e}$ has reviewed the question of neighboring group participation in radical reactions, including a number of systems in which anchimeric acceleration (but not by neighboring sulfur) for the $\mathrm{BrCCl}_{3}$ addition was sought. In no case, however, has he identified an unequivocal example of neighboring sulfur bridging in radical additions to olefins.

Registry No.-3, 51130-00-8; 4, 3698-28-0; 5, 300-57-2; 6a, 51635-32-6; 6b, 51635-33-7; 6c, 42006-80-4; cis-7, 51635-35-9; trans7, 51635-37-1; 11a, 51635-38-2; 11b, 51635-39-3; 16, 51635-40-6; 17, $51635-41-7$; 18, 51635-42-8; 19, 51635-43-9; cis-19, 51635-44-0; 20, 51635-45-1; 21, 51635-46-2; 22, 51635-47-3; 24, 39984-76-4; 25, 51635-48-4; 27, 51635-49-5; trans-28, 51130-01-9; cis-28, 51635-50-8 threo-29, 51635-51-9; erythro-29, 51635-52-0; 30, 51635-53-1; 31, $51635-54-2 ; 34,637-50-3 ; 35,4285-49-8 ; \mathrm{BrCCl}_{3}, 75-62-7 ; \mathrm{HCO}_{2} \mathrm{H}$ 64-18-6; $\mathrm{I}_{2}, 7553-56-2 ; \mathrm{H}_{2} \mathrm{O}_{2}, 7722-84-1 ; N, N$-dimethyl-S-o-allylphenylthiocarbamate, 51635-55-3; o-allylphenol, 1745-81-9; sodi. um thiophenolate, 930-69-8; 4-bromo-1-butene, 5162-44-7; sodium benzylthiolate, 3492-64-6; 5-bromo-1-pentene, 1119-51-3; thioanisole, 100-68-5; 2,4-dinitrobenzenesulfonyl chloride, 528-76-7; 0 -[3chloro-2-[(2,4-dinitrophenyl) thio]propyl] anisole, 51635-56-4; 0 -[3chloro-2-[(2,4-dinitrophenyl)sulfonyl]propyl]anisole, 51635-57-5.

Miniprint Material Available. Full-sized photocopies of the miniprinted material from this paper only or microfiche $(105 \times$ $148 \mathrm{~mm}, 24 \times$ reduction, negatives) containing all of the miniprinted and supplementary material for the papers in this issue may be obtained from the Journals Department, American Chemical Society, 1155 16th St., N.W., Washington, D. C. 20036. Remit check or money order for $\$ 3.00$ for photocopy or $\$ 2.00$ for microfiche, referring to code number JOC-74-2157.

\section{References and Notes}

(1) S. Winstein and R. Buckles, J. Amer. Chem. Soc., 64, 2780 (1962).

(2) For reviews of this subject see (a) $\mathrm{S}$. Winstein, Bull. Soc. Chim Fr., 18, C55 (1951); (b) K. D. Gunderman, Angew. Chem., Int. Ed. Eng/., 2, $599(1963)$; (c) A. Streitwieser, Jr., Chem. Rev., 56, 675 (1956); (d) B. Capon, Quart. Rev., Chem. Soc, 18, 45 (1964).

(3) S. Winstein, C. R. Lindegren, H. Marshall, and L. L. Ingraham, $J$ Amer. Chem. Soc., 75, 147 (1953).

(4) (a) M. L. Bender, J. Amer, Chem. Soc., 79, 1288 (1957); (b) W. Hanstein, H. J. Berwin, and T. G. Traylor, ibid, 92, 829 (1970).

(5) Where $G$ is the participating group (here RS $=G$ ) and $n$ is the size of the ring in the transition state; see (a) R. Heck and $\mathrm{S}$. Winstein J. Amer. Chem. Soc. 79, 3105, 3114 (1957); (b) S. Goodman and S. Winstein, ibid., 79, 4778 (1957); (c) S. Winstein, E. Allred, R Heck, and R. Glick, Tetrahedron, 3, 1 (1958)

(6) (a) This is patterned on the concepts of W. v. E. Doering and H. H Zeiss, J. Amer. Chem. Soc., 75, 4773 (1953), applied to solvolysis and displacement reactions without neighboring group participation (b) A recently debated? proposal that both SN1 and SN2 involved ion-paired intermediates has been reviewed: $R$. A. Sneen, Accounts Chem. Res., 6, 46 (1973)

(7) See for a full discussion of alternative viewpoints (a) D. J. Raber J. M. Harris, R. E. Hall, and P. v. R. Schleyer, J. Amer. Chem. Soc., 93, 4821 (1971); (b) R. A. Sneen and H. M. Robbins, ibid. 94, 7868 (1972).

(8) H. Kwart and M. T. Waroblak, J. Amer. Chem. Soc., 89, 7145 (1967).

(9) D. J. Cram, J. Amer. Chem. Soc., 71, 8363 (1949); 74, 2129 (1952).

(10) W. Winstein, B. K. Morse, E. Grunwald, K. C. Schreiber, and J. Corse, J. Amer. Chem. Soc. 74, 1113 (1952)

(11) For a fuller discussion of alternative interpretations in controversy see (a) M. G. Jones and J. L. Coke, J. Amer. Chem. Soc., 91 4284 (1969); (b) C. J. Kim and H. C. Brown, ibid., 91, 4286, 4287, 4288 (1969); (C) H. C. Brown, C. J. Kim, C. J. Lancelot, and P. V. R. Schleyer, ibid., 92, $5244(1970)$

(12) P. D. Bartlett, "Non-Classical lons," W. A. Benjamin, New York, N. Y., 1965.

(13) C. J. Lancelot and P. v. R. Schleyer, J. Amer. Chem. Soc., 91, 4291 (1969).

(14) C. J. Lancelot, J. J. Harper, and P. v. R. Schleyer, J. Amer Chem. Soc., 91,4294 (1969)

(15) C. J. Lancelot and P. v. R. Schleyer, J. Amer. Chem. Soc., 91 4296, 4297 (1969).
(16) For further discussion see W. A. Pryor, "Free Radicals," McGrawHill, New York, N. Y., 1966

(17) (a) J. E. Bujake, M. W. T. Pratt, and R. M. Noyes, J. Amer. Chem. Soc. 83, 1547 (1961); (b) S. W. Benson, J. Chem. Phys., 38, 1945 (1963).

(18) P. D. Bartlett and C. G. Swain, J. Amer. Chem. Soc., 71, 1406 (1949).

(19) A G. Ogston, E. R. Holiday, and L. A. Stockton, Trans. Faraday Soc., 44, 45 (1948).

(20) H. Bohme and K. Sell, Ber., 81, 123 (1948)

(21) R. Gratz and P. Wilder, Jr., Chem. Commun., 1449 (1970)

(22) L. A. Paquette, G. V. Meehan, and L. D. Wise, J. Amer. Chem. Soc., 91, 3231 (1969).

(23) P. D. Wilder, Jr., and L. Felin-Oterno, J. Org. Chem., 30, 2570 (1965).

(24) (a) A. de Groot, J. A. Beerma, and H. Wynberg, Tetrahedron Lett., 2365 (1968); (b) R. Crawford and C. Woo, Can. J. Chem., 43, $3178(1965)$

(25) T. Ichi, Y. Tamaru, and Z. Yoshida, J. Amer. Chem. Soc., 91, 5170 (1969).

(26) H. Goering and K. Howe, J. Amer. Chem. Soc., 79, 6542 (1957)

(27) A. Knipe and C. Sterling, J. Chem. SoC. B, 1218 (1968)

(28) R. Breslow, L. Kaplan, and D. LaFollette, J. Amer. Chem. Soc., 90, 4051, $4056(1968)$

(29) G. Baddeley, J. Chem. Soc., 663 (1950).

(30) H. Morita and S. Oae, Tetrahedron Lett., 1347 (1969).

(31) W. Mueller, J. Amer. Chem. Soc., 91, 1223 (1969).

(32) J. C. Martin and R. J. Basalay, J. Amer. Chem. Soc., 95, 2565 2572 (1973).

(33) D. J. Raber and J. M. Harris, J. Chem. Educ., 49, 60 (1972).

(34) R. Heck, J. Corse, E. Grunwald, and W. Winstein, J. Amer. Chem. Soc., $79,3278(1957)$.

(35) (a) Z. Horri, J. Tsuil, and T. Inoi, Yakugaku Zasshi, 77, 248 (1957); Chem. Astr., 51, 8672a (1957): (b) S. Oae and Y. Yano. (1957); Chem. Astr., 51, 8672
Tetrahedron, 24, 5721 (1968).

(36) (a) W. L. Orr and N. Kharasch, J. Amer. Chem. Soc., 75, 6030 (1953); (b) C. Brown and D. Hogg, Chem. Commun., 357 (1965).

(37) (a) D. R. Hogg, Quart. Rep. Sultur Chem., 339 (1967); (b) D. J. Pettitt and G. K. Helmkamp, J. Org. Chem., 29, 2702 (1964).

(38) (a) G. H. Schmidt, Can. J. Chem., 46, 3757 (1968); (b) D. H. Mueller and P. E. Butler, J. Amer. Chem. Soc., 88, 2866 (1966); 90,2075 (1968); (c) D. C. Owsley, G. K. Helmkamp, and M. F. Rettig, /bid, 91, 5239 (1969)

(39) T. Jacobs, R. Macomber, and D. Zunker, J. Amer. Chem. Soc., 89 7001 (1967).

(40) N. Kharasch and A. J. Havlik, J. Amer. Chem. Soc., 75, 3734 (1953).

(41) G. H. Schmid and V. M. Csigmadia, Can. J. Chem., 44, 1338 (1966).

(42) G. Beverly and D. Hogg, Chem. Commun., 138 (1966).

(43) H. Kwart and L. J. Miller, J. Amer. Chem. Soc., 83, 4552 (1961).

(44) P. Wilder, Jr., and L. Felin-Otero, J. Org. Chem. 31, 4264 (1966).

(45) See, for example, C. Walling and W. Heimreich, J. Amer. Chem. Soc. $81,1144(1959)$.

(46) See, for examples, (a) G. A. Russell, J. Org. Chem., 23, 1407 (1958); (b) J. A. Howard and K. U. Ingold, Can. J. Chem., 41, 1744 (1963): (c) C. Walling and B. Miller, J. Amer. Chem. Soc., 79, 4181 (1957); (d) G. A. Russell and R. C. Williamson, ibid., 86, $2357(1964)$

(47) R. E. Pearson and J. C. Martin, J. Amer. Chem. Soc., 85, 3142 (1963).

(48) (a) A. T. Blomquist and. A. J. Buselli, J. Amer. Chem. Soc. 73, $3882(1951)$; (b) A. T. Blomquist and 1. A. Bernstein, ibid., 73, 5546 (1951); (c) C. G. Swain, W. H. Stockmayer, and J. T. Clarke, ibid., 72, 5426 (1950); (d) H. H. Jaffe, Chem. Rev., 53, 191 (1953); (e) W. Cooper, J. Chem. Soc., 3106 (1951).

(49) W. G. Bentrude and J. C. Martin, J. Amer. Chem. Soc., 84, 1561 (1962).

(50) D. L. Tuleen, W. G. Bentrude, and J. C. Martin, J. Amer. Chem. Soc., 85, 1983 (1963).

(51) T. H. Fisher and J. C. Martin; J. Amer. Chem. Soc., 88, 3382 (1966).

(52) D. J. Pasto, G. R. Meyer, and S. Kang, J. Amer. Chem. Soc., 91, $2163(1969)$

(53) R. C. Fahey and R. A. Smith, J. Amer. Chem. Soc., 86, 5035 (1964).

(54) W. Winsteln and N. J. Holness, J. Amer. Chem. Soc., 77, 5562 (1955).

(55) M. J. S. Dewar and R. C. Fahey, J. Amer. Chem. Soc., 85, 2245 $2248(1963)$

(56) C. H. Collins and G. S. Hammond, J. Org. Chem., 25, 911 (1960).

(57) D. C. Owsley, G. H. Helmkamp, and S. N. Spurlock, J. Amer Chem. Soc., 91, 3606 (1969).

(58) A. Streitwiester, Jr., "Solvolytic Displacement Reactions," McGraw Hill, Now York, N. Y., 1962, p 95.

(59) G. Collin, et al., J. Prakt. Chem., 311(2), 238 (1969).

(60) H. C. Brown, R. S. Fletcher, and R. B. Johannesen, U. Amer. Chem. Soc. 73,212 (1951)

(61) J. G. Traynham, A. G. Lane, and N. S. Bhacca, J. Org. Chem., 34 1302 (1969).

(62) P. S. Skell and R. C. Woodworth, J. Amer. Chem. Soc., 77, 4638 (1955).

(63) P. S. Skell and P. F. Readio, J. Amer. Chem. Soc., 86, 3334 (1964).

(64) P. S. Skell, D. L. Tuleen, and P. D. Readio, J. Amer. Chem. Soc. $85,2849,2850(1963)$ 
(65) For further discussion pro and con the occurrence of bridged radicals see (a) P. S. Skell, R. D. Woodworth, and J. H. MCNamara, $J$ Amer. Chem. Soc. 79, 1253 (1957); (b) P. I. Aboll and L. $H$ Piette, ibid. 84, $916(1962)$; (c) N. P. Neureiter and F. G. Bordwell, ibid. 82, 5354 (1960); (d) B. A. Bohm and P. I. Abell, Chem. Rev., 62, 599 (1962). (e) L. Kaplan, "Bridged Free Radicals." Marcel Dekker, New York, N. Y., 1972, p 305.

(66) H. Kwart and E. R. Evans, J. Org. Chem., 31, 410 (1966).

(67) R. Adams and R. E. Rindfusz, J. Amer. Chem. Soc., 41, 648 $(1919)$.

(68) The sole basis for assigning the trans configuration to this compound was that it represented the predominant isomer; the trans would be expected to be favored sterically over the cis owing to lesser steric interactions of the methyl groups.

(69) The absorption of the protons in $\mathrm{CH}_{3} \mathrm{Cl}$ occurs at $3.05 \mathrm{ppm}$. The absorption of protons in $\mathrm{CH}_{3} \mathrm{Br}$ occurs at $2.68 \mathrm{ppm}$ : J. Dyer, "Applica- tions of Adsorption Spectroscopy of Organic Compounds," Prentice-Hall, Englewood Cliffs, N. J., 1965, p 75

(70) (a) Trichloromethyl and 0 -thioanisole are considered the "large" groups. (b) The major component of the mixture was designated as the threo diastereoisomer based on the coupling constant for the methine

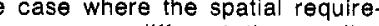
ments of "large" and "small" groups are very different, the coupling constant for methine protons is greater than $10 \mathrm{~Hz}$ in the erythro. isomer and less than $5 \mathrm{~Hz}$ in the threo isomer: C. A. Kingsbury and W. B. Thornton, J. Org. Chem., 31, 1000 (1966); L. M. Jackman and S. Sternhell, "Applications of Nuclear Magnetic Resonance Spectroscopy in Organic Chemistry," 2nd ed, Pergamon Press, Elmsford, N. Y., 1969, op 163, 291-292. (c) This nmr was determined from the $\mathrm{nmr}$ of the mixture by cancelling the contribution made by erythro-29.

(71) N. Kharasch and M. M. Weld. Anal. Chem., 27, 966 (1955).

\title{
A Stereochemical Approach toward the Structure of Gas-Phase Ions ${ }^{1 a}$
}

\author{
Mark M. Green,*1b J. Michael Moldowan, and John G. McGrew, II \\ Department of Chemistry, University of Michigan, Ann Arbor, Michigan 48104
}

Received December 10, 1973

\begin{abstract}
The stereoselectivities for hydrogen abstraction in the electron impact induced loss of acetic acid from three 1,2-disubstituted ethyl acetates as well as the loss of water from three acyclic secondary alcohols have been determined. This information was sought in an attempt to (1) help define the general limits for conformational analysis in the study of gas-phase ions and (2) determine the structural relationships, fundamental to conformation, among the various gas-phase ions and accessible phase molecules studied. In each case, i.e., elimination of acetic acid and loss of water, the results are stereochemically comparable to the analogous thermal reactions, i.e., formation of olefins from the pyrolysis of the subject acetates and 1,4-hydrogen abstraction by the alkoxy radicals derived from the alcohols studied. The overall results may be seen as a stereochemical extension of the historical structure-reactivity approach to ion structure in inaccessible gas-phase molecular radical cations. The success of these stereochemical experiments, along with the results of others in related studies, clearly recommends this type of approach to the elucidation of the nonbonded features of gas-phase ion structure unavailable by present methodology.
\end{abstract}

The molecular radical cations produced by electron impact and studied in mass spectrometers are now recog. nized as effective models for understanding the behavior of numerous intermediates in condensed phase. ${ }^{2}$ The study of such condensed-phase intermediates is one of the central themes of modern organic chemical research and therefore work on the structure of their mass spectral potential counterparts is important. While interest in such questions in gaseous ion chemistry has led to various methods for structure correlation and elucidation, ${ }^{3}$ there is a continuing need for information on the relationship between accessible molecules subject to conventional probes and those encountered in mass spectrometry. In the present work we have chosen two different electron impact induced hydrogen abstracting elimination reactions which appear superficially analogous to certain thermal reactions. For each of these reactions we have compared the stereochemical prerequisites in the transition state of hydrogen abstraction (i.e., thermal vs. electron impact) by determining the relative transfer of competitive diastereotopic hydrogens. For both electron-impact reactions the stereochemical course measured in this way is exactly parallel to the compared thermal reactions. These results strongly suggest that the compared reacting molecules are closely corresponding in structure.

Electron Impact Induced Elimination of Acetic Acid. Earlier work on the electron impact induced (EI) elimination of acetic acid from acetates ${ }^{4}$ showed, in analogy to the situation in pyrolysis, ${ }^{5}$ that hydrogen is abstracted primarily from the $\beta$ carbon. Since the detailed stereochemistry of the pyrolysis is known, ${ }^{5,6}$ the corresponding sets of $\beta$-eliminations suggest looking at the mass spectral counterpart stereochemically to determine the depth of analogy (Scheme I).

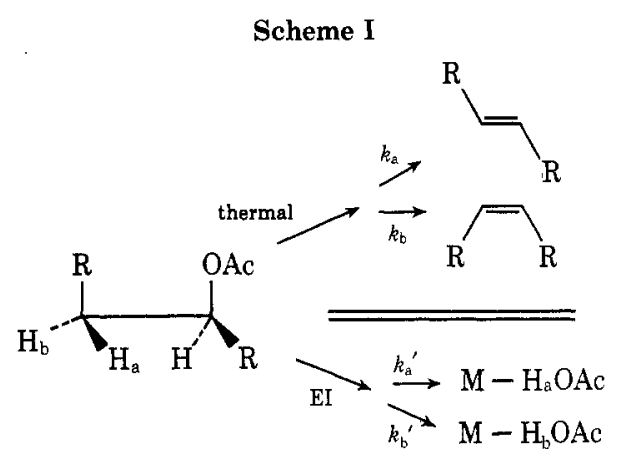

As outlined in Scheme I, our objective is the kinetic discrimination between the diastereotopic hydrogens, ${ }^{7,8}$ $\mathrm{H}_{\mathrm{a}}$ and $\mathrm{H}_{\mathrm{b}}$. This necessitates preparation of the deuterated diastereomers of the subject acetates (Scheme II).

Scheme II<smiles>[R]C([2H])C([R])OC(C)=O</smiles>

1, $\mathrm{R}=\mathrm{CH}_{3}$

3, $\mathrm{R}=\mathrm{C}_{6} \mathrm{H}_{3}$

5, $\mathrm{R}=\alpha$-naphthyl

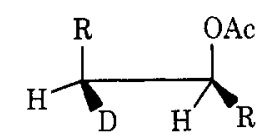

2, $\mathrm{R}=\mathrm{CH}_{3}$

4, $\mathrm{R}=\mathrm{C}_{6} \mathrm{H}_{5}$

6, $\mathrm{R}=\alpha$-naphthyl
While the labeled acetates 1-4 were prepared following the literature, ${ }^{6} 5$ and 6 were both synthesized from trans. 1,2-di- $\alpha$-naphthylethene via lithium aluminum deuteride opening of the epoxide and deuterioboration, respectively. ${ }^{9}$

Table I exhibits the mass spectral data for loss of acetic acid from these deuterated materials. 